\title{
The Reform of a New Grinding in M7150A Grinder
}

\author{
Wang Shaoni ${ }^{1, a}$ \\ ${ }^{1}$ Shandong Polytechnic, Jinan, 250104, Shandong, China \\ azni1978@126.com
}

Keywords: Reform, Grinder, a New Grinding

\begin{abstract}
There are some defects with the M7150A grinder grinding, such as, cooling is unsatisfactory, lubrication is poor, axial movement is large. These problems are safety risks in the actual production, and easily lead to bearing burst and machine shutdown. For more than a few problems, the author conducted a reconstruction of the new model grinder grinding, which proved more efficient.
\end{abstract}

\section{Introduction}

The surface grinding machine is mainly used for machining flat of mechanical parts; and it is an important process equipment in the machinery industry [1]. The whole structure of M7150A grinder used in the writer's factory and produced by Shanghai Machine Tool Works in 1983 is very complex. The grinder uses hydraulic and mechanical joint feeding mode. In the 1980's, in accordance with national requirements of eliminating high-energy motor, the grinding machine electrical control system has been modified by the factory, with the drive to replace the intermediate frequency generator, reducing the energy consumption of the machine. However, the mechanical structure has not been changed much and has been in use ever since. Due to the structural design and prolonged use, there are some drawbacks [2]:

1. Because there is no special cooling system, the grinder often stops running and is unable to continue working, as a large amount of heat caused by the high speed grinding is not easily discharged.

2. Because the grinder uses pumps for lubrication, the heat dissipation and lubrication effect is poor.

3. Fan bearing can reduce axial movement. At the same time it is able to keep balanced. But this structure has led to a lower precision, making it difficult to achieve actual demand.

In order to solve these above-mentioned problems, the grinder grinding head should be reformed under reasonable cost control.

\section{Present Situation Investigation}

The three defects of M7150A grinder grinding leads to high speed grinding and causes heat to build up in actual operation so that the bearing bursts and the processing can't continue. There are also great security risks. After the bearing bursts, the spindle is seriously damaged and does not work properly. If the spindle is replaced, the maintenance costs will increase significantly. These problems not only affect the processing quality and efficiency of the products, but also affect the timely completion of production tasks [3]. So the grinding grinder should be improved.

In order to solve the problems of the burst bearing and damage to the spindle in the process, improved should be the three structural defects of grinding that grinding temperature is too high, the fuel supply makes heat dissipation difficult and the fan bearing is misalignment. Only by addressing these defects, the grinding performance and processing accuracy can be improved.

\section{Modification Scheme}

According to currently available technology, the designed modification schemes are as follows: 
1. A wind net grinding cooler is designed by the principle that wind is generated when the spindle rotates at high speed. The cooler could make the heat discharged by means of the wind, so the problem that the cooling effect of grinding is not ideal is solved, and it will not occur that the bearing bursts and the grinder is stopped [4]. The cooler installation diagram is shown in Figure 1 and Figure 2.

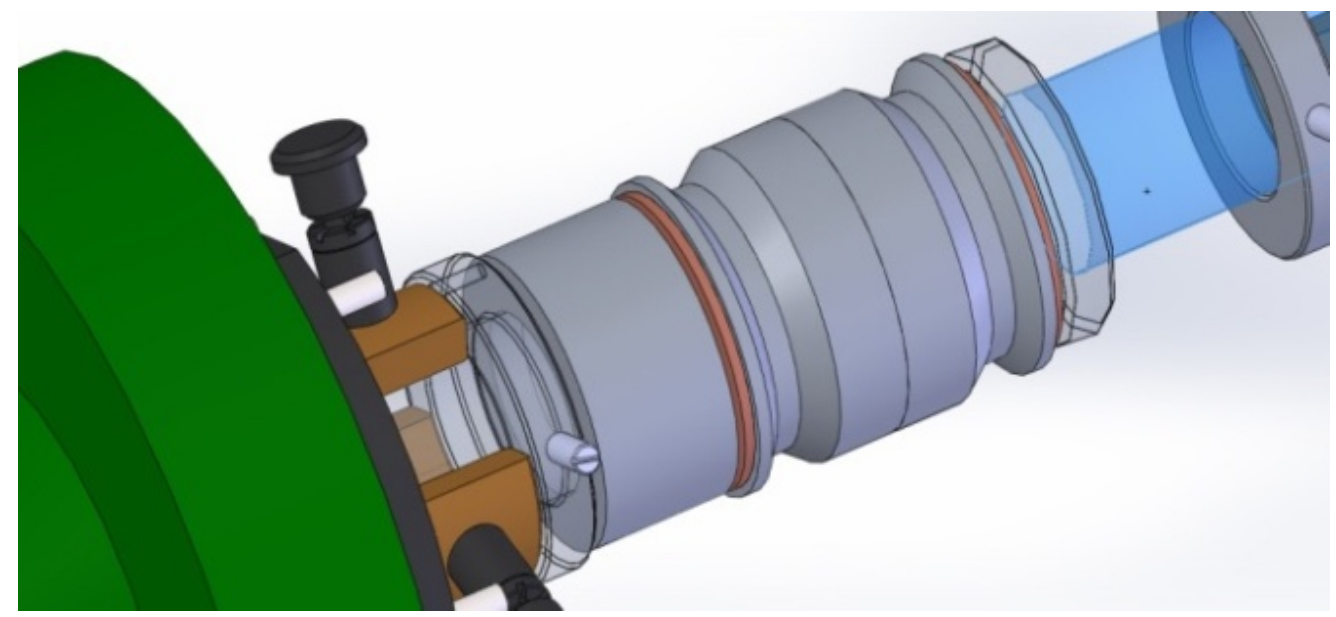

Fig.1 Before cooler installed

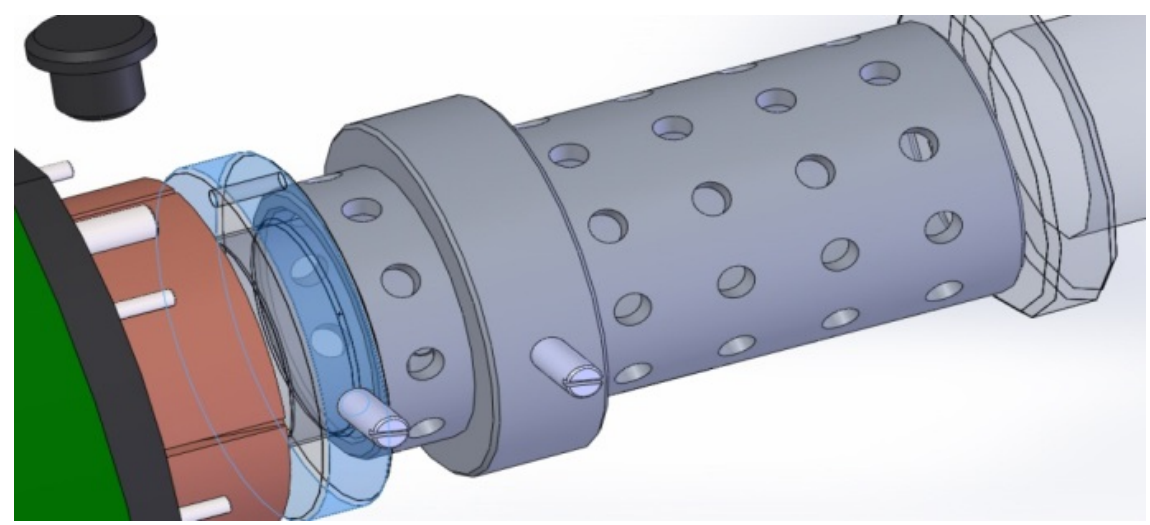

Fig. 2 After cooler installed

2. In order to change the way of fuel supply, a spindle rotary vacuum suction device by siphon principle is designed. In the bottom of the concentric bearing, a $\Phi 5$ hole is drilled, one end of which is connected with the pipeline and the filter hermetically, and the other end of which is connected with the spindle closely to form a closed container. When the spindle rotates at high speed, creating a vacuum within the container, the oil is sucked into the hole, to achieve the purpose of lubrication. Vacuum suction is easy to implement, and the fluid contact area with the spindle increases [5]. It is easy to heat, and to ensure good lubrication. Bearing transformation diagram is shown in Figure 3.

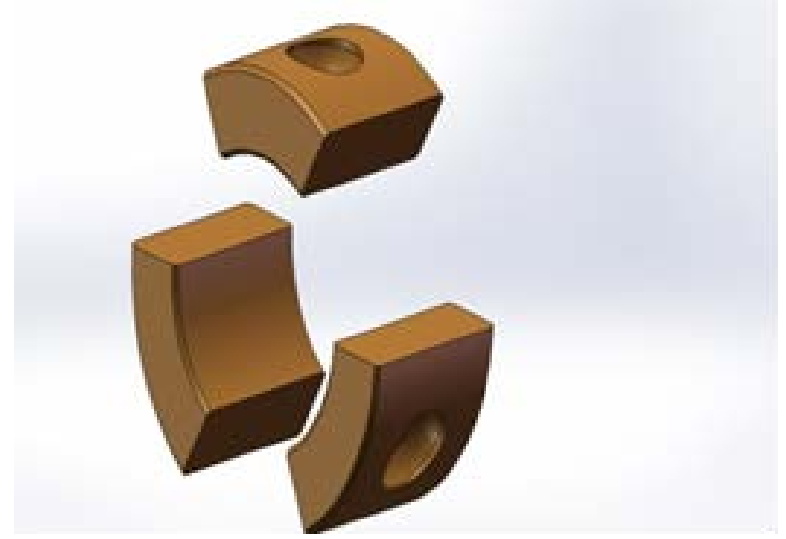

Fig. 3 bearing transformation by changing fuel supply style

3. In order to change the fan bearing axial movement controlled manner, a conical concentric bearing control axial movement is used. Fan Bearing is difficult to operate, it is difficult to identify 
the concentricity, but the cone concentric bearing is easy to operate, good concentricity is automatically formed after assembly [6]. Thus, concentricity and balance of grinding spindle components can be improved, so the grinder runs smoothly, and machining accuracy is improved. Bearing transformation diagram is shown in Figure 4.
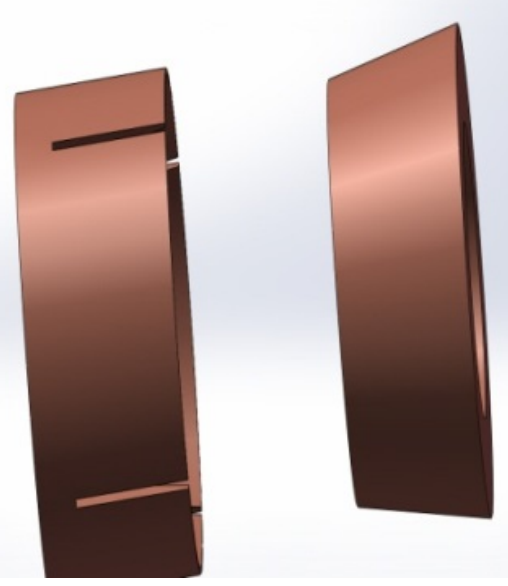

Fig. 4 after bearing transformation by using a conical concentric bearing

\section{Application Effect}

The air network cooler that is designed solves the problems of bearing burst and machine shutdown caused by spindle's overheat, and fills the gap of the technology. The cooler is machined easily and can be used in lathes and grinders. It has the following characteristics:

1. Good cooling effect

The results have showed that the spindle temperature of machine tool installed wind net cooler can only reach $20^{\circ} \mathrm{C}$, but the spindle temperature of machine tool without cooler can reach $80^{\circ} \mathrm{C}$.

2. Good generality

In the writer's factory, all the boring and milling machines, grinders and lathes have been installed with this cooler. The cooling effect is good, and the equipment performance and machining efficiency have been improved greatly.

3. Good economic benefit

In the writer's factory, there are ten M7150A grinders and fifteen CA6140 lathes. Take them as example, the reform could save production cost greatly.

First, it can save maintenance costs. On average, four times a year have occurred for bearing burst and machine shutdown of the lathes and grinders without wind network cooler and the spindle needs to be replaced with bearings and related accessories four times. Each time the maintenance cost is about $¥ 8,326$, the four times maintenance cost is in total $¥ 33,304$ per year. In the writer's factory, there are twenty-five machine tools, saving maintenance costs $¥ 832,600$ each year.

Second, it can reduce downtime losses. It will take about five days that the device is repaired each time. According to working eight hours a day with processing profits $¥ 45$ per hour, the total loss of processing profits is $¥ 1,800(5 * 8 * 45)$ for five days; and the factory will spend $¥ 180$ on wages of workers' working five days, so maintenance losses of each machine is ¥1,980 (1800+180) every time. The maintenance losses is in total $¥ 7,920(1980 * 4)$ four times per year, there are twenty-five machine tools in the writer's factory, so it can reduce downtime losses $¥ 198,000$ (7920*25) per year, if the wind network cooler is installed.

Third, it can reduce cooling maintenance expenses. From May to October every year, we need to cool the equipment, and each device needs to configure a $340 \mathrm{~W}$ industrial fans. Each fan works for about ten hours and consumes $3.4 \mathrm{kw} / \mathrm{h}$ degrees a day. In six months, the twenty-five fans need to consume $15,300 \mathrm{kWh}(180 * 3.4 * 25)$, and cost $¥ 11,475(15300 * 0.75)$. The price of industrial fan is $¥ 425$, and twenty-five fans will cost $¥ 10,625(25 * 425)$ in total. After being installed the cooler, the 
fans are no longer needed; the expenditure can be reduced to zero. So we could reduce cooling maintenance expenses ¥22,100 (11475+10625).

According to the above-mentioned analysis, the factory could reduce expenses $¥ 1.0527$ million every year, if the grinding is transformed, and the economic benefit is notable.

\section{Conclusion}

By the reconstruction, we could overcome the three structural defects of grinding, avoid the bearing burst and machine shutdown, reduce maintenance costs, improve the grinder performance, machining accuracy, quality and efficiency. The grinder runs stably and meets the demands of production. Since the model grinder is a product of the planned economy era, and there are several decades of production history, so domestic users is enormous. Our experience with the transformation has value to popularize.

\section{References}

[1] Zhou Shanqi. Experimental Research and simulation on the temperature field of spindle system of high precision surface grinding machine tool [J], 2012.6.

[2] Xu Zihai, Fu Changlin, Sun Xiangzhong. M7120A surface grinder grinding spindle oil spill improvements [J]. Laigang Science \& Technology, 20052 (116), 20-23.

[3] Qu Guilong. Improvement of internal doublerun drill grinding [J]. Machinist Metal Cutting, 2003 8, 61-63.

[4] Xie Yingkai. Improvement of M7130 grinder grinding [J]. Machinist Metal Cutting, 2003 8, 20-21.

[5] Hong Shanliang. Cooling measures of vertical grinding wheel head [J]. Manufacturing Technology \& Machine Tool, 1983 4, 17-18.

[6] Li Jiefu. M7120A surface grinder grinding axle causes and elimination [J]. Energy Conservation, 2014 4, 77-79. 